\title{
VIOLÊNCIA DOMÉSTICA NA PERSPECTIVA DE GÊNERO E POLÍTICAS PÚBLICAS
}

\section{DOMESTIC VIOLENCE FROM GENDER PERSPECTIVE AND PUBLIC POLICIES}

\author{
Anna Paula Garcia Oliveira* \\ Vanessa Ribeiro Simon Cavalcanti ${ }^{* *}$
}

\begin{abstract}
Oliveira APG, Cavalcanti VRS. Violência doméstica na perspectiva de gênero e políticas públicas. Rev Bras Crescimento Desenvolv Hum 2007;17(1):39-51.

Resumo: O objetivo deste artigo é analisar a violência nas relações entre mulheres e homens, dentro do espaço doméstico e familiar, identificando fatores que fazem muitas mulheres não quebrarem os ciclos desse fenômeno nos quais estão inseridas. A pesquisa quantitativa foi realizada no acervo da Delegacia Especial de Atendimento à Mulher de Salvador-Bahia, no período de janeiro a dezembro de 2003, apontando a desistência na primeira etapa do procedimento punitivo dos seus agressores como maioria dos casos. Em nenhum dos quatro casos estudados, verificou-se cumplicidade e consentimento feminino ante a violência sofrida, mas antes uma luta por igualdade nas relações de gênero e de reação a uma realidade injusta que é a da violência contra a mulher.
\end{abstract}

Palavras-chave: Gênero. Violência. Políticas Públicas. Bahia.

\section{INTRODUÇÃO}

$\mathrm{Na}$ atualidade discute-se a exigência consistente de uma maior igualdade de direitos entre mulheres e homens, mas que trazem consigo resistências originárias de uma cultura patriarcal milenar, opressiva às mulheres, tornando-as alvo de violência, especialmente no espaço doméstico.

A violência se tornou um tema freqüentemente analisado nos dias atuais em razão de contar com uma maior visibilidade, através de maciça divulgação pela mídia e pela internet, sem contar com campanhas, ações do governo e de instituições civis enfocando a questão. Especificamente a violência de gênero no espaço doméstico tratase de uma reação a uma relação desigual e, por isso, discriminatória, mas intimamente ligada à violência, traduzida pela lei, como delito e a promovida pelo Estado.
Violência seria, portanto, toda e qualquer ação que torna o outro coisa, objeto desprovido de desejo, da autonomia, da autodeterminação. Embora se manifeste de múltiplas formas, as que nos interessam aqui são aquelas geradas na relação de desigualdades entre homens e mulheres, relação hierarquizada, que confere ao homem a posição de mando e a mulher a posição de submissão ${ }^{l}$ (p.176).

Esse paradigma se encontra tão cristalizado nas relações de gênero que parece ser natural essa hierarquia e, conseqüientemente, o uso da força para mantê-la. É paradoxal esse modelo relacional uma vez que, apesar de ser conferido ao homem o "poder", este por si só não é suficiente, necessitando ser garantido pela força física masculina. $\mathrm{O}$ poder como posição privilegiada de mando é compreendido aqui como um exer-

\footnotetext{
Delegada de Polícia do Estado da Bahia há dez anos, formada em Direito pela UCSAL e Mestra em Família na Sociedade Contemporânea pela Universidade Católica do Salvador, Brasil. Email: annangui@ig.com.br

** Doutora em História pela Universidade de Leon. Professora do Mestrado em Família na Sociedade Contemporânea da UCSAL. Email: vanessa.cavalcanti@uol.com.br
} 
cício, possuindo um caráter relacional e disseminado por toda estrutura social. E onde há luta para a manutenção desse poder há resistência².

Essa definição de violência se aproxima muito da elaborada por Marilena Chauí ${ }^{3}$ que a considera toda e qualquer violação da liberdade e do direito de alguém ser sujeito constituinte de sua própria história. Liberdade aqui entendida como ausência de autonomia. A violência então seria toda e qualquer ação que torna alguém desprovido de autonomia ou causa a sua violação, estabelecendo assim uma "condição geral de subordinação".

Heiremans, por exemplo, afirma em seus estudos sobre o tema que violência é "uma forma de exercer poder sobre alguém situado em uma posição de inferioridade ou de subordinação na escala hierárquica". ${ }^{4}$ (p.23). (grifos nossos).

Percebe-se que poder e hierarquia são categorias inseridas no significado de violência, que ainda traz consigo valores culturais enraizados como o patriarcado gerando, com a busca por igualdade e liberdade das mulheres, novas situações de conflitos. Indica um poder que produz domínios e rituais de verdade com a intenção de adestrar, de impor uma "docilidade-utilidade" com o objetivo de manter a própria dinâmica social ${ }^{2}$. Fazendo um recorte, no caso das relações de poder entre mulheres e homens, se percebe bem essa intenção de sujeição, baseada numa graduação da autoridade e seguindo critérios impostos pela cultura.

É sob este recorte da violência que surge a discussão sobre as suas manifestações no âmbito doméstico, tendo como principais atores sociais as mulheres e os homens. Este trabalho se interessa pela violência, seja como ação ou omissão, que atinge a autonomia da mulher como sujeito e por se encontrar numa relação desigual com o homem, impondo-se a ela, uma posição de submissão tanto no espaço público como no privado.

Este fenômeno "cristaliza" uma hierarquia, fortalecendo-a e proporcionando uma internalização da desigualdade que a caracteriza, como modelo das relações entre os sexos. "A desigualdade, longe de ser natural, é posta pela tradição cultural, pelas estruturas de poder, pelos agentes envolvidos na trama de relações sociais" "5.71). Apesar de enraizada essa visão de que a desi- gualdade entre os sexos faz parte da natureza, ela foi e é construída pelas instituições sociais.

Analisando as construções sociais que cristalizam a violência nas relações conjugais e os inúmeros casos de violência doméstica envolvendo homens e mulheres, em audiências e procedimentos policiais na Delegacia Especial de Atendimento à Mulher - DEAM de Salvador-Bahia, surge o interesse na discussão sobre essa violência, sob os aspectos de gênero e das Políticas Públicas implementadas no Brasil nas últimas décadas.

A mulher cede às pressões tanto externas como internas que justificam, pelo menos para ela, desistir da punição estatal ao seu agressor. Essas pressões consistem na influência da ordem patriarcal nas relações sociais de gênero como os simbolismos de uma dominação masculina que cercam essas relações, principalmente as conjugais. Pretende-se então, sugerir questões que levem a uma explicação para a permanência dessa mulher na relação agressiva, no sentido de enriquecer o debate sobre este tema com elementos da literatura especializada como também com os dados recolhidos na análise dos registros policiais, dentre algumas inferências justificadoras dessa situação.

\section{Violência Doméstica, Gênero, Patriarcado e Dominação: categorias de análise}

Embora de forma superficial, a violência doméstica se mostra particularmente complexa, pois agressor e agredida estão ou estavam ligados por laços de intimidade e afetividade que, muitas vezes, fazem essa situação de violência ser estendida, e também encontra certa cumplicidade do Estado até porque estão sendo violados acordos e convenções internacionais de direitos humanos.

Há quem alegue que eles não podem ser identificados como causas da violência no sentido causa-efeito 4 . Outros criam teorias para justificar a ocorrência desse fenômeno, como a 'da provocação feminina à autoridade masculina' ou estabelecem fatores que evitariam a incidência da violência entre homens e mulheres (Hogget \& Pearl apud ${ }^{4}$ ).

Este trabalho adota a "Teoria do Patriarcado", elemento que sustenta a idéia de que o ma- 
rido é proprietário da mulher, dela podendo dispor da forma que achar mais conveniente, como se fosse um objeto, uma propriedade sua. Seria a base da violência marital como muitos investigadores da área das Ciências Sociais afirmam.

Todos os escritos legais, históricos, literários e religiosos contribuem para se entender o status desigual da mulher, explicando porque as mulheres foram transformadas em "vítimas adequadas da violência marital”. Os únicos papéis permitidos às mulheres no mundo real e no imaginário sempre foram o de esposa, mãe, filha, amante, prostituta ou santa. E quando as mulheres se apresentam com uma identidade distinta da prescrita, a mesma é desvalorizada e castigada. ${ }^{6}$ (p.56).

O patriarcado apresenta "justificativas" para sustentar a situação de violência nas relações conjugais aceitas pela sociedade como crenças. A imagem de esposa ideal, obediente ao seu marido, fiel apesar de traída e a valorização de habilidades masculinas como a de controlar a esposa e corrigila quando necessário caracterizam essa ideologia. São condicionamentos sociais, onde se segue um padrão que não deve sofrer alteração na sua dinâmica, estabelecida pelo "habitus" e alicerçada pelo aparelho ideológico do patriarcalismo, determinando identidades e valores tanto para homens como para as mulheres.

A violência contra a mulher "é uma manifestação do sistema de dominação que é exercido historicamente do homem sobre a mulher"4 (p.29), sistema que predetermina uma identidade feminina que quando oposta ao esperado faz, daquela, alvo de agressões e de discriminações.

Com uma conotação mais ampla, pode-se mencionar Olívia Rangel ${ }^{7}$ que se refere à violência contra as mulheres ou doméstica e ainda há autores que propõem chamar de violência intrafamiliar. Este artigo se detém na busca da compreensão do fenômeno da violência contra a mulher no contexto doméstico-conjugal: como são formuladas as políticas públicas voltadas para essa problemática, bem como buscar fatores que implicam na decisão da mulher, tendo procurado a delegacia de polícia, manifesta desinteresse na investigação da sua denúncia, seja ela expressão da sua dor física, como nos casos de lesões corporais, seja psicológica e moral, quando ela é acuada e constrangida por ameaças.

Para melhor entender o fenômeno da violência praticada contra a mulher, tão combatido pelo movimento feminista até os dias atuais, é crucial que se faça um mergulho nas categorias de análise da dominação masculina sobre as mulheres no cenário da modernidade, mencionando que, pela categoria gênero, entende-se como sendo uma categoria mais geral, "como conjunto de normas modeladoras dos seres humanos em homens e em mulheres..." ${ }^{5}$ (p.70), e que trazem a lume uma abordagem relacional.

Ao se tratar da violência de gênero, não se está determinando que ela só configure entre homens e mulheres, mas é neste tipo relação que este fenômeno é mais difundido uma vez que as estruturas de poder e as tradições culturais construíram, e ainda constroem, com certa freqüência, as desigualdades de gênero ao longo da história. Gênero é todo e qualquer tipo de construção de perfis e modelos para seres humanos em homens e mulheres, expressas nas relações destas duas categorias sociais.

Nesse sentido, ressalta-se a necessidade de ampliar este conceito para as relações homemhomem e mulher-mulher, enfatizando também uma perspectiva sobre opção ou orientação sexual. Apesar de estar ligado às diferenças biológicas, entre homens e mulheres, gênero é uma construção cultural do que se chama de atributo masculino e feminino. Existe uma expectativa cultural em relação a cada sexo, sendo o gênero um sistema de distinção social norteado pelas diferenças percebidas entre eles. Sexo e gênero são uma unidade, havendo uma interação entre eles, apesar do primeiro estar vinculado ao aspecto biológico e o outro a uma formulação cultural ${ }^{5}$.

Uma grande crítica que se faz ao conceito de gênero é sua amplitude, podendo ser identificada à idéia de construir-se a partir de "imagens que as sociedades constroem do masculino e do feminino"5 (p. 58), sendo um consenso, como também uma característica, de não necessariamente explicar desigualdades entre homens e mulheres.

As diferenças entre homens e mulheres pertencem ao domínio da natureza, o que contraria 
a ideologia de gênero que produz uma naturalização de atribuições sociais nessas diferenças de sexo. A cultura, onde brotou o conceito de igualdade, acaba apresentando-se como uma cultura de gênero, onde através das diferenças sexuais estas são "engendradas", naturalizando o masculino e o feminino e normatizando as condutas de mulheres e homens.

Retornando à análise sobre o patriarcado, ressalta-se que há dois tipos: um que seria individual, caracterizado pelas crenças de gênero, crenças estas que determinam serem os homens superiores e as mulheres inferiores nas suas relações, comportando o uso de violência no caso de reação a esta situação. O outro seria o chamado estrutural, que seria constituído das mesmas crenças de gênero na esfera individual, mas praticadas e reforçadas pelas instituições do Estado como a polícia, justiça, poder legislativo, as políticas sociais e públicas do Estado, o sistema de saúde pública, a economia e a própria sociedade. Percebe-se que o patriarcado individual é reforçado pelo estrutural não dando margem às mulheres de construir um projeto de reação que consiga modificar tal situação ${ }^{6}$.

As feministas se dividem em três correntes quanto à adoção do conceito de patriarcado ou de gênero. Uma primeira corrente adere ao conceito de patriarcado estritamente enquanto a segunda ao de gênero, desconsiderando o de patriarcado. Há uma terceira vertente que acredita que a história é o processo onde se admite a utilização do conceito de gênero, como categoria geral para toda a história, e o de patriarcado, como uma específica de determinado período. ${ }^{5}$

Esta pesquisa adota essa terceira corrente de pensamento, não desvalorizando a produção de conhecimento validada pelas outras, mas acreditando que a categoria do patriarcado é o que alimenta e, porque não afirmar, legitima a desigualdade entre mulheres e homens em todos os espaços, em que as relações entre essas duas categorias sociais possam ser verificadas, sem exceção.

Diferentemente de gênero, o patriarcado não permite nenhuma perspectiva de alternância nas posições de dominador e dominado, sendo o homem seu "legítimo" detentor. Como a ideologia patriarcal é insuficiente para garantir a obediência da vítima, necessário se faz o uso da violência. Ao se constatar que o patriarcado representa uma estrutura de poder presente, inclusive nos espaços públicos, vê-se que o Estado age influenciado por essa ideologia, legitimando através de políticas públicas, ou pela ausência delas, a desigualdade dos direitos das mulheres.

Em relação à dominação, esta por si só é uma violência simbólica, vez que instituída pela adesão do dominado ao dominador e à própria dominação. Apresenta-se para quem é atingido por seus efeitos, como uma relação "naturalizada". Ademais, há uma subordinação que se estabelece como parte integrante das relações entre os envolvidos desse processo.

A própria Saffioti ${ }^{5}$ entende que dominaçãoexploração é uma coisa única, não admitindo territórios distintos. Esse processo de opressão não consiste apenas no exercício do poder de uma categoria social contra outra, mas na exploração seja econômica, com as limitações impostas pelo mercado de trabalho, ou sexual da mulher, controlando sua sexualidade como um todo. Não se impõe apenas a obediência, mas o abuso e o domínio sobre esses aspectos.

A dominação requer a aquiescência dos subordinados enquanto que o poder é exercido mesmo contra a vontade desses. Nesse contexto, algumas autoras como Saffioti ${ }^{5,9}$, Rangel ${ }^{7}$, Hasanbegovic ${ }^{6}$ e outras entendem que pode até se verificar uma possível contribuição das mulheres na produção da violência de gênero. Excluem uma "possível cumplicidade feminina" nesse fenômeno, atribuindo às mulheres uma consciência de dominadas. Ou como Hasanbegovic ${ }^{6}$, que entende que o grau de tolerância da mulher com a violência depende de sua vulnerabilidade no campo ideológico, econômico ou pessoal, da gravidade da violência sofrida e do medo que ela tenha do parceiro.

Ao se mencionar tolerância feminina à violência, é necessária uma análise do que é ser cúmplice de uma ação ou omissão, quando aflora a característica de uma participação de outro como colaborador dessa. Ser cúmplice não é apenas aderir, mas colaborar em algo, participar com o outro e fazer uma parceria com este na prática de algum fato. Diverge de consentimento 
que consiste em permissão. Consentir, permitir ou tolerar alguma coisa, aprovando expressamente ou então aquiescendo de alguma forma com a ação do outro.

Posicionamentos como os do vitimismo ou da provável cumplicidade das mulheres nas situações de violência com seus parceiros, se intensificaram nas décadas de 70 e 80 , quando essa idéia foi difundida pelo movimento feminista. A mulher era considerada como sujeito não constituinte, um ser passivo e vitimado.

“...violência masculina contra a mulher perpassa todas as camadas sociais, sem negligenciar o peso de condições econômicas negativas, nem tampouco de mediações psicológicas que explicam condutas radicalmente distintas de agentes sociais vivendo sob circunstâncias idênticas; jogando, muito oportuna e sabiamente, com suas vivências ${ }^{7}$ (p.1).

Não cabem mais afirmações que sustentavam que a violência contra a mulher está diretamente ligada à pobreza ou a falta de acesso à educação. A violência doméstica ocorre em bairros nobres das grandes metrópoles, em faculdades, envolvendo mulheres com certo grau de escolaridade, perpassando por todas as classes sociais e gerações.

Sabe-se que a violência expressa um conflito de interesses e no caso da violência de gênero, entre os dos homens e os das mulheres. Há a vontade de quem domina (o homem), que se apresenta tanto no mandar como na constituição de um sistema que garanta a satisfação plena de seu objetivo, sistema este que podemos identificar como sendo o patriarcado.

O que alguns autores como Saffioti ${ }^{5}$, Rangel ${ }^{7}$, Mathieu ${ }^{11}$ e outros questionam, é a associação feita entre vítima e passividade. Falarse em mulher vítima é correto, pois elas são o principal alvo do fenômeno violência conjugal. Entretanto, não se deve é, ao utilizar-se dessa terminologia, retirar a possibilidade de reação e superação à relação violenta em que a mulher se encontra. Até porque, apesar dela encontrar-se 'numa condição de subalternidade', nem por isso fica passiva, manifestando reações ou resistindo ao domínio masculino com pequenos boicotes como deixar de executar certos serviços domésticos ou não deixar de ir a determinado lugar dito proibido pelo homem.

Posicionar a mulher como vítima indefesa, sem condições de reação, implica em tornar 'natural' a violência da qual ela é alvo. O fundamental é perceber essa mulher como "sujeito constituinte de seu próprio destino" (p.2). A hipótese de Rangel consiste em considerar as mulheres como sujeitos com consciência mediatizada pela ideologia machista. São sujeitos com consciência de dominados. A construção da consciência das mulheres se fez de forma a tornálas dominadas, submissas à dominação masculina, acreditando serem incapazes de opor uma resistência eficiente no processo de igualdade entre os sexos.

Não se percebe uma oposição entre a abordagem de Chaui ${ }^{3}$ e Rangel ${ }^{7}$ nesse contexto. Tanto uma como a outra acreditam que a subjetividade ou a própria consciência feminina estão relacionadas indiretamente com a ideologia machista. É através desta que o homem, por sua vez, percebe a mulher como não-sujeito, transformando a diferença em desigualdade.

Há uma percepção errônea de que a mulher consente com sua subordinação aos homens, como categoria social. Mas, o que se dá realmente é que "o consentimento representa apenas a aparência do fenômeno na medida em que a consciência das dominadas é distinta da consciência dos dominantes"5 (p. 4).

As posições hierárquicas são antagônicas e o consentir expressa uma assimetria nas relações. Não se pode considerar que a falta de reação à violência signifique consentir com ela. Ao se ponderar na existência de consentimento e, portanto, de cumplicidade, promove-se, como salienta Mathieu ${ }^{11}$, a consciência oprimida em livre, retirando-se a culpa do opressor. Ademais, a mulher sucumbe à violência de gênero não só por uma dependência econômica, mas principalmente por uma dependência afetiva construída pela dominação simbólica que, além de definir formas de comportamento masculinas e femininas, faz com que se manifestem estruturas mentais que incorporam subjetivamente imagens 
comportamentais, como as de que o homem é forte e dominador, a mulher é frágil e submissa.

Essas estruturas acabam sendo inscritas nas identidades de mulheres e homens e, dessa forma, mantêm as relações entre eles assimétricas. A imagem feminina construída culturalmente é o grande obstáculo para as mulheres vencerem a submissão salientando que:

as mulheres estão conformadas subjetivamente desta forma não por razões biológicas ou "naturais" nem porque são geneticamente inferiores aos homens. E sim porque os valores patriarcais estão inseridos na subjetividade consciente e inconsciente das mulheres. E isso não pode ser resolvido por um ato de vontade ${ }^{7}$. (p.7).

Os valores patriarcais constituem um verdadeiro sistema de opressão da mulher, legitimando uma desigualdade incabível entre os gêneros. A relação entre mulheres e homens sob o domínio da ideologia patriarcal, comporta certa indulgência por parte da sociedade, permitindo que, para ter cumprido seus preceitos e verdades, a força seja utilizada contra o pólo mais fraco, geralmente a mulher, oprimida e explorada ao longo da história da humanidade.

As diferenças biológicas de homens e mulheres não servem para respaldar a conformidade que se sobressai de forma avultosa do comportamento feminino, especificamente daquelas que vivem em situação de violência de gênero. Há a aparência de que existe uma superioridade masculina, garantida pelo patriarcado e internalizada na subjetividade das mulheres. Essa conformação consciente, e talvez inconsciente da mulher, é que dificulta a tomada de uma decisão quanto à quebra do ciclo da violência.

\section{Políticas públicas: DEAM de Salvador-Bahia}

Políticas Públicas podem ser entendidas como as respostas do Estado às demandas sociais de interesse da coletividade. São chamadas 'Estado em ação' e implementadas por meio de projetos e ações de governo, voltadas para setores específicos. É necessário que existam parcerias entre Estado e sociedade civil, como o objetivo de se implementar políticas públicas, que não devem ser reduzidas a políticas estatais.

No Brasil, o início da implantação das primeiras políticas públicas direcionadas às mulheres em situação de violência se deu a partir da pressão desenvolvida pelo movimento feminista na década de 70. Ele foi fundamental para o processo de mudança legislativa e social, principalmente nas propostas de políticas públicas ${ }^{10}$.

Segundo essas orientações, em 1980, criou-se em São Paulo um serviço de denúncia e amparo para mulheres em situação de violência doméstica que evidenciou ser esta, um fenômeno que atingia todas as raças, classes, orientações sexuais e gerações, demonstrando possuir um caráter universal, ademais de apontar um 'silenciamento' social em relação a tal tema. Essa abrangência da violência contra a mulher também foi verificada na pesquisa nos documentos selecionados na DEAM de Salvador-Bahia, onde se realizou a análise dos dados obtidos e apresentados neste trabalho, expondo que esse fenômeno social atinge de forma generalizada mulheres de diferentes classes sociais, idades, raças e grau de instrução.

O S.O.S. Mulher demonstrou que as visões sobre este fenômeno eram muito diferenciadas entre as mulheres que ligavam e as que atendiam, principalmente por serem de camadas sociais diferentes. Apesar de ter consciência da opressão que sofriam, as mulheres pareciam entendê-la como natural, sendo necessário atentar para as particularidades de cada história de violência para não fundamentar cada ato violento de forma genérica $^{12}$.

No ano de 1985 é criada a primeira Delegacia de Polícia de Atendimento à Mulher em São Paulo e, logo nos anos seguintes, foram criadas em vários estados do país. Hoje, essas unidades policiais são chamadas de Delegacias Especiais de Atendimento a Mulher - DEAM. Na Bahia foi aberta a primeira Delegacia de atendimento a mulher em outubro de 1986.

As Delegacias Especiais de Atendimento à Mulher (DEAM's) foram conseqüência das discussões do movimento de mulheres e da realidade violenta em que se encontravam e se 
encontram, as mesmas nesse país, antes escondida entre quatro paredes, que passou a fazer parte da agenda pública.

Como forma eficiente de usufruto de direitos, as políticas públicas devem ter um caráter integralista e sensível à questão de gênero, para melhor atender as demandas femininas e conseqüentemente feministas. Em resumo, como atesta $\operatorname{Saffioti}^{5}$ (p. 46), a principal bandeira do feminismo é a "igualdade social para ambas as categorias de sexo". Afinal, a igualdade entre mulheres e homens na sociedade sempre participou das lutas das feministas muitas vezes transpassadas por outras questões sociais. Para alcançar essa igualdade, que apesar de juridicamente garantida não se tornou real, busca-se nas políticas públicas o atendimento e satisfação das necessidades da mulher no sentido de possibilitar a vivência efetiva dessa eqüidade social.

Diante disso, no final dos anos oitenta e por toda a década de noventa, houve a implantação de serviços de assistência social e de atendimento psicológico para as mulheres. $\mathrm{Na}$ área da saúde pública surgiram serviços ligados à questão do aborto e iniciou-se a criação das Casas Abrigo, com a finalidade de acolher as mulheres em situação de violência e seus filhos quando não havia outra opção diante da gravidade da situação.

Um dos principais desafios na consolidação de uma política pública na área de gênero é dissolver as resistências políticas e as "naturalizadas", isto é, as internalizadas em cada um. É implementar, através de ações, uma ofensiva contra essa naturalização impregnada na sociedade. Para tanto, se torna fundamental considerar o "saber próprio" dessa mulher em situação de violência, considerando suas experiências e seu discurso, não apenas a ilustrar projetos e planos de ação, mas, como alicerce para políticas públicas eficientes.

As políticas públicas voltadas para as mulheres são as que tendem a universalizar os seus direitos já legalmente instituídos, mas vivenciados por uma minoria privilegiada. Elas fazem correções nas distorções existentes em nossa sociedade, viabilizando o acesso das mulheres aos direitos de qualquer cidadão. São as chamadas "Políticas ou Ações Afirmativas", instrumentos que o Estado possui, voltadas para superar ou ao menos amenizar as desigualdades, defendendo os direitos humanos, no caso os das mulheres, principalmente as que se encontram em situação de violência, na sua integralidade, atentando sempre para as especificidades femininas. Elas priorizam a inclusão social de grupos discriminados como os negros e as mulheres, buscando a redução de disparidades e ampliação da justiça social, associados a direitos específicos ou restritos mas, sobretudo, vistos como direitos humanos, inscritos nas práticas sociais do cotidiano ${ }^{13}$.

As discriminações sociais são um entrave à democracia no mundo atual, tendo-se nas políticas públicas positivas a ferramenta para corrigir as desigualdades, entre elas as de gênero, ainda tão presente nas relações humanas. A implementação de políticas que tendem a buscar, pelo menos minimizar, desigualdades sociais, deve estar voltada para os "sistemas de subordinação", e não apenas se limitar a tentar atingir diferenciais quanto a posições no mercado entre homens e mulheres, mas elevando a quantidade de postos de trabalhos para esses grupos mais discriminados.

Esses dados vêm fortalecendo a justificação para implementação de programas assistencialistas e não emancipatórios para as mulheres, mantendo-as excluídas socialmente. Não há uma consciência pautada no discurso de gênero que faria considerações sobre outras questões que não as referentes aos grupos dos quais essas mulheres interagem.

Geralmente se pensa a mulher mãe, esposa, companheira, provedora às vezes, mas é esquecida a sua condição feminina. Há sempre um apêndice "qualitativo" como se o fato de ser apenas mulher a tornaria inferior, menor, de pouco ou de nenhum valor social.

Não basta a implementação de políticas públicas voltadas para a proteção e segurança de mulheres em situação de violência se em conjunto não existirem ações de caráter educativo e conscientizador para quem precisa do serviço como para quem o fornece. As delegacias de atendimento a mulher são essenciais para a garantia dos Direitos Humanos e internos, mas não o suficiente para o alcance de respostas efetivas as demandas femininas. 


\section{MÉTODO}

\section{Locus da pesquisa}

Em razão disso, foi escolhido como locus de uma pesquisa, em parte apresentada neste artigo, a Delegacia Especial de Atendimento a Mulher de Salvador-Bahia, precisamente os discursos registrados nas ocorrências policiais do ano de 2003. Esta delegacia foi criada em 1986, diante da força dos debates nacionais sobre a questão da violência contra a mulher no Brasil àquela época. Inicialmente foi lhe dado o nome de Delegacia de Proteção à Mulher (DPM), denominação que possuía um aspecto protecionista ilusório e questionado, algumas vezes, pelas próprias mulheres que procuravam seus serviços, ao não considerarem atendidas suas expectativas, pelo menos como esperavam.

Em 2002, foi modificada a sua nomenclatura e construída uma sede nova com espaço para, além do atendimento policial ininterrupto, setores como o de apoio psicológico e de serviço social. Mesmo com uma sede nova e completa, e com servidores com experiência no atendimento às mulheres em situação de violência doméstica, o acesso às novas instalações da DEAM não é tão fácil como o anterior.

O prédio fica em uma parte alta da cidade, cercada de ladeiras, não sendo próximo à avenida de grande circulação, além de distante do Instituto Médico Legal, local em que são realizadas as perícias nas mulheres violentadas física e sexualmente. Fora isso, não houve inicialmente uma capacitação completa de todos os policiais para melhor utilizar os novos recursos tecnológicos da delegacia, como no caso dos computadores, uma vez que na antiga sede todo o registro era manual, perdendo-se, além de muito tempo neste procedimento, informações importantes para a investigação. Apesar de possuir um material humano relativamente capacitado para o serviço a ser prestado, ele ainda não é suficiente para a demanda, sendo recente a necessidade de estabelecer número de senhas para atendimento, excetuando os casos de emergência.

As DEAM's de todo o país, como política pública que são, vêm representando um espaço de acolhimento e de prestação de atendimento especializado para as mulheres em situação de violência doméstica. No ano de 2003 foram registradas 7.769 ocorrências policiais na DEAM de Salvador. Deste número, 71 mulheres foram vítimas em 2003 de crimes de lesões corporais e/ ou ameaça, pelo menos em dois registros, cujos autores dos fatos foram apontados por elas como sendo seus esposos ou companheiros, excluídas, como se percebe, as ocorrências policiais com outras modalidades criminosas que não as citadas acima e as envolvendo os ex-maridos, ex-companheiros, noivos, namorados e outros parentes do sexo masculino. Destas, 42 mulheres desistiram expressa ou tacitamente da atuação policial, seja manifestando desinteresse na lavratura do Termo Circunstanciado (forma expressa), seja não comparecendo nem ao menos na audiência preliminar que, nos casos de ameaça e em alguns de lesão corporal, são realizadas pelas policiais da própria DEAM.

\section{A base documental}

Especificamente neste trabalho, os registros policiais selecionados para estudo foram do período de janeiro a dezembro de 2003, sendo escolhido este período, por ser o primeiro ano completo da Delegacia Especial de Atendimento a Mulher (criada em outubro de 1986, em Salvador-BA com o nome de DPM - Delegacia de Proteção à Mulher) na sede nova, localizada no bairro do Engenho Velho de Brotas em Salvador, já que a delegacia foi transferida em março de 2002, e as referentes a lesões corporais e ameaças, havendo em alguns casos, audiências policiais realizadas no início de 2004. O material analisado foram às ocorrências policiais da DEAM de Salvador-Bahia, que assistiram aos seguintes critérios:

1. Casos de desistência manifestada ou implícita quanto ao prosseguimento nos procedimentos policiais referentes aos crimes de lesão corporal de natureza leve, com base em laudo oficial, e crime de ameaça, salientando que ambos os crimes necessitam de representação criminal para acionar o Estado;

2. Registros realizados no período de janeiro de 2003 a dezembro do mesmo ano na DEAM 
de Salvador-Bahia, feito por mulheres que foram agredidas por homens com quem conviviam maritalmente ou estivessem casadas e que tivessem ido a unidade policial de forma espontânea, isto é, sem serem conduzidas por policiais militares, àquela unidade policial.

Depois de selecionados os casos que atenderam a esses critérios, foram separados os em que constava desistência expressa da vítima, motivada ou não. As mulheres que retornaram à Delegacia na data marcada na ocorrência foram em número de quatro e, em alguns desses casos, não há motivação clara da desistência. Os casos de desistências representam as mulheres que no ano de 2003 não concluíram a primeira etapa do procedimento punitivo do agressor, que tem início na Delegacia.

\section{RESULTADOS}

A análise documental realizada levantou informações que foram corroboradas pelas categorias anteriormente discutidas neste artigo. Fazendo um recorte apenas nos quatro casos de desistência expressa, um dos relatos apresenta, como justificativa, a tentativa de resgate da relação conjugal, mostrando como a relação entre vítima e agressor, na violência marital, é amarrada por laços de afetividade que a tornam tão complexa.

Presentes às partes, a comunicante e o autor do fato, O S., [...] alega este que estão tentando recuperar o relacionamento, vivendo em harmonia, tendo $O$, modificado seu comportamento estando mais amoroso com a comunicante, estando consciente de suas obrigações de pai e companheiro... (BAHIA. DEAM, AUDIÊNCIA REALIZADA, 2004 - Casal C.J.R., mulher de 25 anos e O. S., homem de 24 anos. Ocorrência registrada em 2003 e audiência realizada em 8 de março de 2004).

Percebe que o homem é quem relata primeiro colocando a tentativa de resgate da relação e em seguida a mulher passa a justificar sua desistência alegando que o parceiro modificou seu comportamento, ressaltando sua amorosidade e compromisso com a família e com ela.

A mulher mantém a conjugalidade sob esse tipo de alegação, de cunho afetivo, pois existe a idéia de que a culpa pela falência da relação é geralmente dela. $\mathrm{O}$ mesmo se dá com a família, esta desempenha um papel de solidificação de valores e influência, fortemente, na decisão de seus membros.

As duas ocorrências registradas por C.J.R.na DEAM de Salvador-Bahia em 2003, foram na modalidade criminosa de lesões corporais, uma no mês de fevereiro e a outra em dezembro, e em ambas expedidas guias para exame pericial, tendo ela se submetido aos dois exames. A audiência se deu meses depois do último registro podendo esse lapso temporal ter influenciado na desistência.

As ocorrências policiais registradas por C.S.F. se deram nos meses de janeiro e outubro de 2003, ambas de desistência, mas só na primeira, ela manifestou expressamente seu desinteresse, sendo esta na modalidade criminosa de lesões corporais e a última de agressão física sem lesão.

[...] a queixosa ratificou todo o teor desta ocorrência policial, assegurando não ter, de imediato, interesse na lavratura de termo circunstanciado, solicitando, apenas que fossem feitas advertências ao queixado para que não volte a apresentar a mesma conduta. O queixado [...] negou a acusação, alegando que teria reagido à atitude agressiva da queixosa, que teria lhe aplicado um murro na face... (BAHIA, DEAM, DEPOIMENTO, 2003 - Casal C.S.F., mulher de 29 anos e S.V.A, homem de 32 anos. Ocorrência registrada em 2003 e depoimento prestado em 31 de janeiro de 2003).

Não há uma motivação clara neste depoimento, mas diante da exposição de S.V.A., de que teria reagido a uma agressão da companheira e esta não ter negado tal ato, supõe-se que sua desistência foi fruto de arrependimento, pois considerou ter uma parcela de culpa. Houve um pedido de separação do queixado, o que motivou a discussão, comprovando que a relação já estava desgastada, o que foi corroborado pelo segundo 
registro, onde C.S.F. afirma que seu marido a estava traindo e por conta disso, eles estavam se desentendendo. Bastou para essa mulher que seu marido fosse advertido pela Delegada de Polícia, apesar da gravidade do seu ato, e posteriormente desistiu outra vez.

A terceira ocorrência não aborda o motivo da desistência de forma clara, apenas demonstra a comunicante que, apesar de ter sido ameaçada pelo companheiro, seu interesse era poder pegar seus pertences, pois havia sido impedida de retornar para o lar, e que ele fosse aconselhado pelo serviço social da delegacia.

Presentes as partes, a vítima manifestou desinteresse em representar criminalmente contra o autor do fato Sr. E.M.O, [...] pois seu interesse é pegar seus pertences e ver o companheiro ser aconselhado pelo serviço social desta DEAM. Encaminhados para a assistente social... (BAHIA, DEAM, DEPOIMENTO, 2003 - Casal E.J.C., mulher de 39 anos e E.M.O, homem de 49 anos. Ocorrência registrada em 2003 e depoimento prestado em audiência, 2 de junho de 2003).

Há uma percepção nítida de que a dominação simbólica está presente nessa relação, influenciando a decisão dessa mulher, pois esta já incorporou comportamentos de submissão. A imagem de mulher ideal e obediente é fortalecida pelas justificativas castradoras apresentadas pelo patriarcado, estipulando os papéis e condutas permitidos. Pelo menos duas ocorrências fazem menção, demonstrando ser comum que um aconselhamento e/ou advertência policial são suficientes para a queixosa, como resposta do Estado à situação de violência pela qual passou. Sugere esta constatação de que seria uma punição ou serviria como instrumento transformador do comportamento do seu parceiro, uma repreensão feita por outra mulher, pela sua conduta.

O último caso de desistência expressa analisado foi na modalidade de ameaça e também de agressão física, conforme depoimento na ocorrência policial:

A queixosa convive com o queixado há 12 anos, tendo 2 filhos, confirmando todo o teor desta queixa, alegando que ainda foi ameaçada com um faca, vez que aquele fez compras e levou para outra companheira, culminando naquela descobrir. Que não tem mais interesse no queixado e já entrou na justiça com a separação legal do casal. Dada palavra ao queixado, este diz que aquela vem sempre "provocando" o mesmo, e ameaçando o referido, dizendo que iria registrar queixa contra o mesmo para prejudicá-lo. Admite ele que está mantendo uma relação com outra pessoa, pois a relação com a queixosa estava findando, $e$ diz que já saiu de casa desde 19/09/2003. Atesta que fez algumas compras para a outra companheira pagar depois, e a queixosa descobriu, culminado numa discussão e agressão física, e admite que pegou a faca para intimidá-la apenas, pois não seria capaz de praticar qualquer ato contra a queixosa. Afirma o mesmo, que ela também pegou a faca para ameaçá-lo, mas ele pegou um jarro no intuito daquela deixar a faca. Diz que está ciente da separação do casal. A queixosa por hora, delibera em não processá-lo. (BAHIA. DEAM, DEPOIMENTO, 2003 - Casal L.P.A, mulher de 33 anos e A S.H., homem de 31 anos. Ocorrência registrada em 2003 e depoimento prestado em audiência em 29 de setembro de 2003).

Observa-se que o agressor utiliza a provocação como justificativa para seu comportamento. Neste ponto, podemos relembrar as análises do capítulo anterior sobre esta questão: como se diante do comportamento, dito provocativo, da esposa, ele pudesse tudo, inclusive desferir murros, conforme relato de L.P.A., no histórico do registro, e ameaçá-la com uma arma.

Apesar dessas mulheres terem desistido, tomando a iniciativa de forma espontânea, de quebrarem com o ciclo de violência em que se encontravam, demonstraram que, mesmo envolvidas no processo de dominação-exploração, subordinandose ao seu parceiro, não consentiram em continuar no papel de vítimas, reagindo ao denunciarem.

\section{CONCLUSÃO}

Diante dessas constatações, é necessário que não se perca a perspectiva de que, em nenhum 
dos casos estudados, verificou-se cumplicidade e consentimento feminino. Houve sim, uma luta por igualdade nas relações de gênero e de reação a uma realidade injusta que é a da violência contra a mulher.

Essa pesquisa pretendeu sugerir questões que possam trazer explicações para esse fenômeno, diante de tantos casos de violência doméstica, envolvendo homens e mulheres, nas audiências e em procedimentos policiais na Delegacia Especial de Atendimento a Mulher - DEAM de Salvador-Bahia, e a constatação da elevada diferença entre os números de registros policiais e os procedimentos encaminhados para a Justiça, demonstrando que da decisão de ir à DEAM até uma ação efetiva, ainda os silêncios prevalecem.

A mulher que cala, que desiste, consente porque se encontra sob o domínio de uma violência simbólica mantida pela cultura patriarcal que é alimentada pela ordem social e permitida pelo Estado. Não só a sociedade encara a violência contra a mulher de forma naturalizada, influenciando através de suas instituições, como a família e a Igreja, ou através da socialização realizada nas escolas (ou melhor, sem privilegiar uma educação não sexista), a manutenção desse quadro, mas também o Estado que não atende às demandas das mulheres de maneira satisfatória por carecer suas políticas de uma gestão eficiente, e de conceitos que ultrapassam a questão de gênero, contudo, apesar de não ser a única variável, está intimamente ligada às desigualdades sociais no país.

O se calar diante das práticas violentas dentro do espaço familiar e a permissividade que decorre desse silêncio são determinados por mecanismos ideológicos tais como o gênero, o patriarcado, a dominação masculina, estabelecendo uma estrutura condicionante para as mulheres, que passam a ter uma realidade de opressão e de violência, aceita e naturalizada pela sociedade. O patriarcado e o consentimento feminino quanto à violência contra a mulher estão intimamente ligados e correlacionados, alimentando um ao outro e conseqüientemente se fortalecendo.

Há a necessidade de se promover alterações na estrutura da sociedade através de mudanças nos paradigmas que sustentam seu arcabouço, seja tentando intervir no modo de produção e nos valores estipulados pelo Mercado, para que se alcance a verdadeira igualdade entre mulheres e homens, ou por meio da promoção de Políticas Públicas - com destaque em saúde e educação voltadas para as mulheres, de programas de combate à violência contra a mulher, de ações específicas.

Verifica-se ainda a necessidade de que as políticas públicas e os serviços tenham um enfoque integral, propondo o empoderamento das mulheres violentadas e envolvendo áreas como a da saúde, segurança, educação e assistência social, o que ainda não foi concretizado. O que dificulta essa efetivação é também a falta de articulação entre os órgãos públicos e as delegacias de atendimento à mulher, principal porta para as denúncias de violência de gênero e doméstica. O reforço a essa visão mais ampla das políticas e serviços de atendimento público pode vir a refletir na auto-estima da mulher, fazendo-a recuperar sua altivez e, sobretudo, servir como instrumento de transformação da sua realidade, tanto nas condições de vida quanto de trabalho.

Percebe-se que a dominação simbólica se faz presente nas relações conjugais analisadas, seja incidindo na decisão da mulher que incorporou comportamentos de submissão ou, pelo menos, de pressões para a manutenção da família ou por questão de dependência financeira, seja na imagem que ela tem do que é ser a "mulher ideal". As justificativas apresentadas - pautadas no patriarcado - reforçam suas condutas e juízos, determinando papéis e expectativas, bastando, muitas vezes para ela, uma advertência policial como resposta do Estado à situação de violência pela qual passou. Essa repreensão feita por outra mulher serviria como "punição", capaz de modificar o comportamento do seu parceiro.

Em nenhum dos casos estudados foi constatada cumplicidade da mulher até porque ela denunciou a situação violenta em que se encontrava, demonstrando reação ao contexto em que estava inserida. Não se deve esquecer que outros interesses podem ter movido algumas dessas mulheres a procurar a DEAM de SalvadorBahia no ano de 2003, que não o desejo de reverter o quadro de violência. Algumas comunicantes 
deixam em segundo plano as agressões sofridas e questionam bens e o patrimônio do casal.

Em um dos relatos foi utilizada a provocação feminina como desencadeador dos atos agressivos dos homens, defendida pela "teoria da provocação". Esse tipo de justificativa apresentado pelos homens, de certa forma, acaba por incluir as mulheres como cúmplices das próprias agressões que sofreram, um verdadeiro absurdo, como se pudesse, assim, respaldar esses comportamentos que mais do que subjetividade é uma questão social/econômica.

Faz-se ainda necessário tecer comentários sobre as inferências quanto a uma possível influência nos casos de desistências aos procedimentos policiais, do lapso temporal entre a comunicação do fato delituoso e a primeira providência adotada pela DEAM, que talvez possa ser objeto de uma outra pesquisa. O que deve ser ressaltado é que essa lacuna na resposta estatal para a mulher que procura a delegacia pode atingir a credibilidade dessa política pública tão relevante para garantia dos direitos das mulheres.

A violência contra a mulher é vista de forma naturalizada pela sociedade que atua influenciando na manutenção dessa idéia seja através da família, da escola e/ou da Igreja, mas também pelo poder público que não acolhe de maneira satisfatória o pleito das mulheres, ao não propor políticas com definições claras sobre as questões de gênero, bem como as ligadas ao território, raça/etnia, classe social e geração. A consolidação de uma política pública na área de gênero tem como principal desafio dissolver as resistências internalizadas por todos os setores sociais, sendo necessário considerar o discurso dessa mulher em situação de violência para servir de alicerce às ações públicas eficientes.

\begin{abstract}
This article aims to analyze violence in the relationships between men and women, inside the home and family space, identifying factors that stop women from putting an end to this phenomenon in which they are inserted. The quantitative research was carried out at the archives of Delegacia Especial de Atendimento à Mulher (Police station for women defense), in Salvador, state of Bahia, from January to December 2003, revealing that many women give up the punishing process of their aggressors in most cases. In none of the four studied cases did we verify complicity or feminine consent before the suffered violence; on the contrary, there is a fight for equality concerning gender relationships and reactions against an unfair reality, which is that of violence against women.
\end{abstract}

Key words: Gender. Violence. Public Policies. Bahia.

\section{REFERÊNCIAS}

1. Moreira MI, Ribeiro S, Costa K. Violência contra a mulher na esfera conjugal: jogo dos espelhos. In: Costa AO, Bruschini C, organizadores. Entre a virtude e o pecado. Rio de Janeiro: Rosa dos Tempos; São Paulo: Fundação Carlos Chagas; 1992. p. 169-90.

2. Foucault M. Microfísica do poder. Rio de Janeiro: Graal; 1999.

3. Chaui M. Participando do debate sobre mulher e violência. In: Perspectivas antropológicas da mulher. Rio de Janeiro: Zahar; 1985. p. 15-27.

4. Heiremans SL. Violência puertas adentro: la mujer golpeada. Santiago de Chile: Ed. Universitária; 1994.
5. Saffioti HIB. Gênero, patriarcado, violência. São Paulo: Fundação Perseu Abramo; 2004.

6. Hasanbegovic C. Violência marital em Cuba: princípios revolucionários vs viejas creencias. Canterbury: Canterbury University Press; 2001.

7. Rangel O. Violência contra a mulher: as desventuras do vitimismo e as armadilhas da cumplicidade. Presença Mulher [periódico na Internet]. $2001 \mathrm{jul} / \mathrm{set}$ [acesso em $15 \mathrm{mar}$ 2005]. Disponível em: http:// www.ubmulheres.org.br/telas/revista/ enc_39.asp.

8. Bourdieu P. A dominação masculina. Rio de Janeiro: Bertrand Brasil; 1999.

9. Saffioti HIB. Contribuições feministas para o 
estudo da violência de gênero. Labrys [periódico na Internet]. $2002 \mathrm{jul} / \mathrm{dez}$ [acesso em 08 mar 2005];(1-2):[38 telas]. Disponível em: http://www.unb.br/ih/his/gefem/labrys1_2/ heleieth1.html.

10. Barsted LL. As mulheres e os direitos humanos: os direitos das mulheres são direitos humanos. Rio de Janeiro: CEPIA; 2001.

11. Mathieu NC. Quand ceder n'est oc consentir: des déterminants matériels et psychiques de la conscience dominée des femmes, et des quelques-unes de leurs interpretations en ethnologie. In: Mathieu NC, editeur.

L'arraisonnement des femmes. Paris: École des Hautes Études en Sciences Sociales; 1985.

12. Gregori MF. Cenas e queixas: um estudo sobre mulheres, relações violentas e a prática feminista. São Paulo: Paz e Terra; 1992.

13. Cavalcanti VRS. Voces femininas: história y organizaciones representativas en Brasil (1975/2002) [tese]. Leon: Departamento de História de la Universidad de Leon; 2003.

Recebido em 17/09/2006 Modificado em 04/10/2006 Aprovado em 10/10/2006 